\title{
Pengembangan Media Pembelajaran Fisika Berbasis Adobe Flash Professional CS6 Untuk Mata Kuliah Fisika Dasar I
}

\author{
Boby Syefrinando*, Suraida, Af Parman \\ Program Studi Tadris Fisika, Universitas Islam Negeri Sulthan Thaha Saifuddin Jambi \\ *Email: syefrinando@yahoo.com
}

Received: 5 Desember 2019;

Accepted: 16 Maret 2020;

Published: 21 Maret 2020

DOI: http://dx.doi.org/10.29303/jpft.v6i1.1522

\begin{abstract}
The aim of this research is to develop learning media based on adobe flash professional CS6 on the subject of mechanics (kinematics and dynamics). In this research produced a product in which several questionnaires were distributed to several experts: media experts, concept experts, linguists, lecturers and students, to find out the validity, practicality and effectiveness of learning media. The research method uses the ADDIE approach (Analysis, Design, Development, Implementation, Evaluation). The results of this study found that the learning media has good indicators. This is evidenced by the results of data analysis obtained from respondents. Based on the assessment of media experts, concept experts and language experts learning media are categorized as very valid, with an average percentage of $91.25 \%$ by media experts, $92 \%$ by concept experts and $100 \%$ by language experts. The practicality of the media obtained $91 \%$ of the responses of lecturers, $84 \%$ of students with very practical criteria. The effectiveness of the media obtained from an increase in student learning outcomes by $0.8 \%$ with high improvement criteria. From the results of the data obtained, this learning media have valid criteria according to experts, practical, and effective and can be used by lecturers and student
\end{abstract}

Keywords: learning media; adobe flash professional cs6; mechanics

\section{PENDAHULUAN}

Pendidikan merupakan proses dalam membentuk kemampuan dasar yang terdiri atas kemampuan berpikir maupun rasa emosi manusia" (Jalaluddin \& Abdullah Idi, 2013). Pembentukan kemampuan dasar tersebut salah satunya ialah kemampuan dasar tentang ilmu yang mempelajari tentang fenomena-fenomena atau tanda-tanda kondisi alam (sains)

Sains atau yang lebih kita kenal dengan nama IPA, berasal dari bahasa latin yang berarti "mengetahui". Fisika yang merupakan cabang ilmu sains mempelajari kejadian-kejadian yang ada di alam, seperti gerak, kalor, tekanan zat cair, bunyi, listrik, magnet dan lain-lain.

Pada pembelajaran fisika sebagian besarnya membahas hal-hal yang bersifat abstrak dan kasat mata ditambah lagi dengan banyaknya rumus dan teori yang harus diingat dan dianalisis. Penyampaian materi yang sifatnya monoton dan biasa-biasa saja karena keterbatasan sarana dan prasarana, dapat lebih mempersulit pemahaman mahasiswa tentang arti atau konsep fisika itu sendiri.

Perbaikan sistem mutu pendidikan nasional merupakan permasalahan besar untuk kualitas pendidikan saat ini. Berbagai carapun dilakukan agar dapat memperbaiki mutu pendidikan nasioanal, diantaranya peningkatan kompetensi guru dan dosen. (Sahidu et al. 2018).

Pada era ilmu pengetahuan, teknologi, dan komputerisasi sekarang akan dapat menjadi sarana dan prasarana dalam membantu pemahaman fisika itu sendiri. Perwujudan dan perkembangan ilmu teknologi yang terus terjadi akan berpengaruh terhadap aplikasi multimedia dalam berkomunikasi dengan komputer 
melalui media berupa teks, gambar, animasi, serta audio dan visual. Dengan dikembangkannya aplikasi multimedia interaktif komputer yang terus akan memudahkan dan membantu proses pembelajaran. Proses pembelajaran fisika secara signifikan dipengaruhi oleh perkembangan di bidang ICT, khususnya pada efektivitas, efisiensi waktu, dan fasilitas pendukung pembelajaran lainnya (Gunawan et al. 2017)

Media pembelajaran merupakan alat bantu dalam menyampaikan pesan pembelajaran. Media Pembelajaran merupakan suatu alat, metode untuk membantu meningkatkan interaksi guru dan siswa selama proses pembelajaran (Hamalik, 1980). Agar hubungan interaksi itu berjalan dengan baik maka dibutuhkan sebuah sarana yang dapat tersampaikan melalui pesan atau media. Pada saat ini, banyak aplikasi untuk mendesain dan membuat media pembelajaran berbasis intraktif yang dapat kita pilih dan yang tepat dalam membangun, mendesain dan mengembangkan sebuah media sehingga menghasilkan sebuah produk yang betul-betul dapat digunakan dan dibutuhkan dalam proses pembelajaran. Aplikasi yang sering digunakan pada saat ini adalah aplikasi Adobe Flash. Adobe Flash adalah sebuah program aplikasi yang dirancang oleh perusahaan Adobe dan digunakan dalam pembuatan animasi, gambar yang berekstensi bitmap, sehingga menghasilkan produk yang sangat menarik, interaktif, dan dinamis baik dalam keperluan mendesain situs web maupun untuk keperluan pengembangan media yang lain (Votecamejo, 2018). Media Pembelajaran ini didesain sesuai dengan kebutuhan materi ajar fisika dasar 1 khususnya mekanika.

Berdasarkan hasil wawancara dengan sejumlah mahasiswa Program Studi Tadris Fisika FTK UIN STS Jambi yang duduk di semester 2, diketahui bahwa masih ada 3 orang dari 35 orang mahasiswa yang berlatar belakang pendidikan bukan dari jurusan IPA pada saat disekolah dulu. Akibat dari latar belakang tersebut membuat mereka belum memahami pelajaran fisika dengan baik.

Berdasarkan hasil angket analisis kebutuhan yang disebarkan sebanyak 20 responden diperoleh $85 \%$ mahasiswa memiliki laptop, $80 \%$ menyatakan sulit memahami konsep mekanika, dosen pengampu belum menggunakan multimedia dalam pembelajaran, fasilitas penunjang tersedia, $100 \%$ mahasiswa membutuhkan media berbasis aplikasi dalam proses pembelajaran Fisika Dasar I.

Oleh sebab itu dengan didesain dan dikembangkannya suatu media pembelajaran ini, kedepannya diharapkan dapat dipergunakan sebagai salah satu alat bantu dalam proses pembelajaran baik di dalam kelas maupun digunakan sebagai bahan belajar mandiri. Media pembelajaran yang akan didesain dan dikembangkan ini yang nantinya akan divalidasi oleh beberapa ahli sehingga media ini layak digunakan dan dapat juga mengurangi suasana belajar yang monoton atau membosankan, membuat proses pembelajaran yang lebih praktis, menarik, menyenangkan, dan efektif.

\section{METODE PENELITIAN}

Penelitian dilakukan pada program studi Tadris Fisika Fakultas Tarbiyah dan Keguruan UIN Sulthan Thaha Saifuddin Jambi. Objek penelitian ini adalah Mahasiswa Tadris Fisika semester I tahun akademik 2019/2020 sebanyak 35 orang pada mata kuliah Fisika Dasar I. Waktu penelitian disesuaikan dengan jadwal mata kuliah yang sudah disusun oleh Program Studi dan disesuaikan pula dengan materi pembelajaran yang akan dijadikan objek penelitian sehingga tidak menganggu proses pembelajaran mata kuliah Fisika Dasar I 
untuk materi Mekanika (Kinematika dan Dinamika).

Penelitian ini merupakan penelitian pengembangan (Research and Devolopment). Pada penelitian ini model yang digunakan adalah ADDIE (Anaysis, Desain, Devolepment, Implementation, and Evaluation). Penelitian ini hanya sampai pada tahapan pengembangan (Devolepment), karena keterbatasan waktu dan biaya.

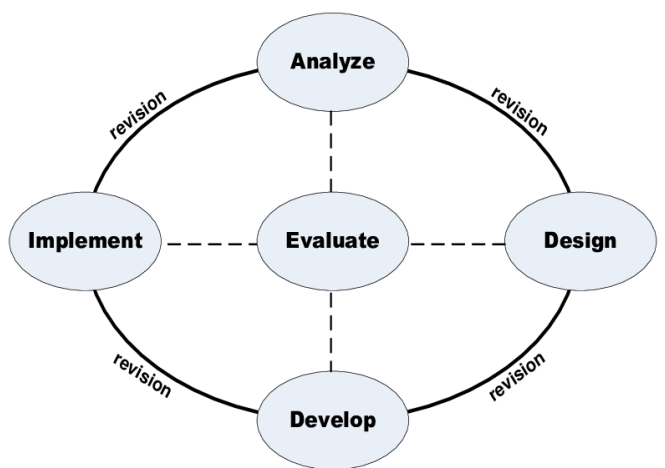

Gambar 1. Pendekatan ADDIE Untuk Pengembangan Produk

(Sugiyono, 2015)

Setelah produk dibuat maka selanjutnya dilakukan uji coba produk untuk melihat tingkat validitas, praktikalitas, dan efektifitas dari media yang sudah dikembangkan.

Analisis data dalam melihat kelayakan dari produk atau media pembelajaran yang dihasilkan dinilai oleh validator ahli media dihitung dengan rumus sebagai berikut:

$$
N P=\frac{R}{S M} \times 100 \%
$$

(Sugiyono, 2015)

Keterangan :

$$
\begin{array}{ll}
\mathrm{NP} & =\text { Nilai presentasi } \\
\mathrm{R} & =\text { Skor penilaian } \\
\mathrm{SM} & =\text { Skor total }
\end{array}
$$

Tabel 1. Kriteria Tingkat Kelayakan Media

\begin{tabular}{cc}
\hline Kriteria & Interval Kriteria \\
\hline Sangat layak & $85 \%-100 \%$ \\
\hline Layak & $70 \%-84 \%$ \\
\hline Cukup layak & $60 \%-69 \%$ \\
\hline Kurang layak & $50 \%-59 \%$ \\
\hline Tidak layak & $<50 \%$ \\
\hline & (Arikunto, 2012)
\end{tabular}

Untuk melihat apakah media pembelajaran itu praktis maka uji kepraktikalitasannya dinilai dari persepsi Dosen dan mahasiswa dengan rumus:

$$
P=\frac{f}{N} \times 100 \%
$$

Keterangan :

$\mathrm{P}=$ Nilai akhir

$f=$ Skor penilaian

$\mathrm{N}=$ Skor total

Tabel 2. Kategori Praktikalitas Media

\begin{tabular}{cc}
\hline Nilai & Kriteria \\
\hline $80 \%<\mathrm{x} \leq 100 \%$ & Sangat praktis \\
\hline $60 \%<\mathrm{x} \leq 80 \%$ & Praktis \\
\hline $40 \%<\mathrm{x} \leq 60 \%$ & Cukup praktis \\
\hline $20 \%<\mathrm{x} \leq 40 \%$ & Kurang praktis \\
\hline $0 \%<\mathrm{x} \leq 20 \%$ & Tidak praktis \\
\hline \multicolumn{2}{c}{ Dimodifikasi dari (Riduwan, 2012) } \\
\multicolumn{2}{c}{ Analisis data efektifnya media }
\end{tabular}

pembelajaran ini dapat dicari dengan rumus berikut :

$$
(g)=\frac{(\bar{X} \text { akhir })-(\bar{X} \text { awal })}{100 \%-(\bar{X} \text { awal })}
$$

Keterangan

(g) : Tingkat Efektivitas

$(\bar{X}$ awal $) \quad:$ Nilai Rata-rata Tes Awal

$(\bar{X}$ akhir $) \quad$ : Nilai Rata-rata Tes Akhir

Tabel 3. Kriteria Efektivitas

\begin{tabular}{cc}
\hline$\langle$ g $>$ gain \% & Kriteria \\
\hline $\mathrm{g}>0,7$ & Tinggi \\
\hline $0,3 \% \leq \mathrm{g} \leq 0,7$ & Sedang \\
\hline $\mathrm{g}<0,3$ & Rendah \\
\hline & (Wiyanto, 2008)
\end{tabular}

\section{HASIL DAN PEMBAHASAN Hasil Penelitian}

Penelitian ini menghasilkan berupa (1) sebuah media pembelajaran berbentuk presentasi animasi pada materi Mekanika yang dikelompokkan menjadi dua pokok bahasan yaitu Kinematika dan Dinamika, (2) penilaian isi atau materi dan desain media, serta penggunaan bahasa yang baik dinilai oleh ahli materi, ahli media, dan ahli bahasa, (3) penilaian (tanggapan) Mahasiswa dan 
Dosen Fisika Dasar I terhadap media yang telah dibuat.

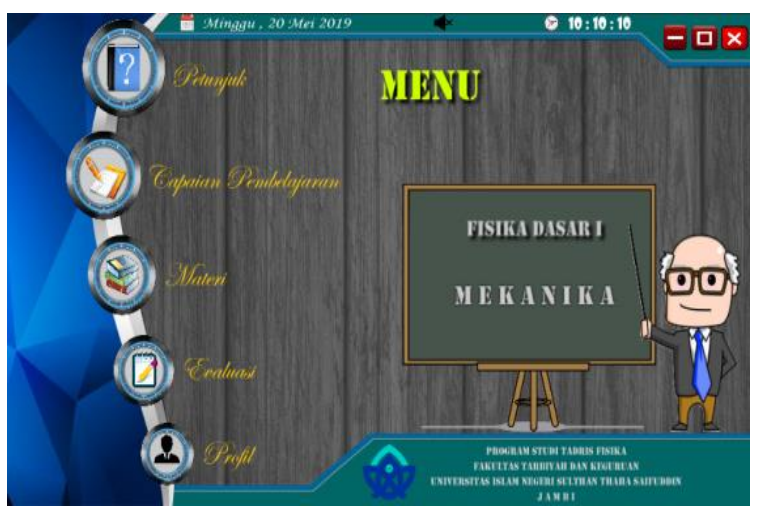

Gambar 2. Tampilan menu
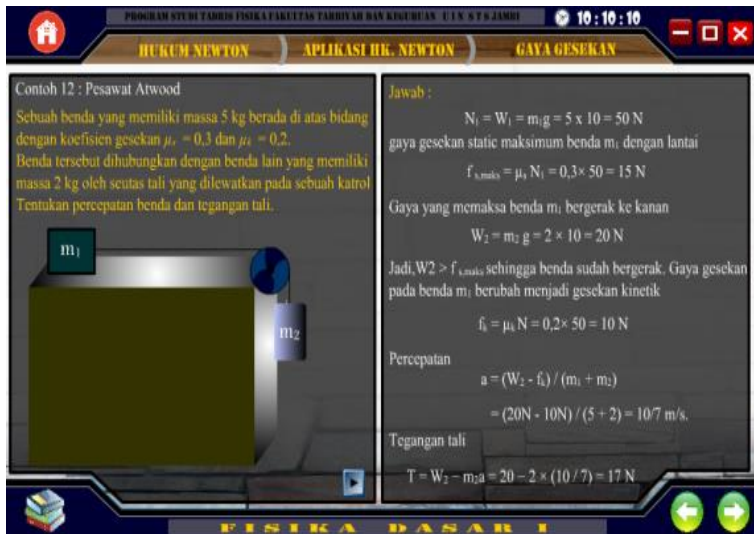

Gambar 3. Animasi dan contoh soal

\section{Validasi Kelayakan Produk}

Untuk menentukan layak atau tidaknya sebuah produk dalam hal ini adalah media pembelajaran yang sudah dikembangkan, maka produk tersebut harus divalidasi oleh para validator yang terdiri dari validator ahli media, ahli materi, dan ahli bahasa.

Tabel 4. Hasil validasi oleh para ahli

\begin{tabular}{lcc}
\hline Validator & Nilai & Kriteria \\
\hline Media & $91.25 \%$ & Sangat layak \\
\hline Materi & $92 \%$ & Sangat layak \\
\hline Bahasa & $100 \%$ & Sangat layak \\
\hline
\end{tabular}

Untuk melihat praktikalitas produk dari media pembelajaran yang telah didesain dan dikembangkan ini, kemudian diuji cobakan atau melihat tanggapan dari Dosen dan Mahasiswa. Respon Dosen dan Mahasiswa dilihat dari angket yang disebarkan.
Tabel 5. Hasil uji coba media

\begin{tabular}{ccc}
\hline Uji Coba & Nilai & Kriteria \\
\hline Kel. Kecil & $84 \%$ & Sangat Praktis \\
\hline Kel. Besar & $87 \%$ & Sangat Praktis \\
\hline Dosen & $91 \%$ & Sangat Praktis \\
\hline
\end{tabular}

Pada tahap akhir ini akan dilakukan uji Efektivitas media pembelajaran dengan memberikan sejumlah pertanyaan berbentuk esay kepada Mahasiswa untuk melihat peningkatan pemahaman hasil belajar Mahasiswa. Pada tahap ini akan dilihat peningkatan pemahaman mahasiswa terhadap pembelajaran Fisika dasar I menggunakan media pembelajaran dengan aplikasi Adobe Flash Professional CS6. Dalam uji efektivitas ini dibagi dengan dua kali sesi test. Test sesi pertama untuk sub pokok Kinematika dan test sesi kedua untuk sub pokok Dinamika.

Tabel 6. Hasil pretes dan postes

\begin{tabular}{ccc}
\hline Komponen & \multicolumn{2}{c}{ Pokok Bahasan } \\
\cline { 2 - 3 } & Mekanika & Dinamika \\
\hline Pretest & 33,43 & 50,29 \\
\hline Postest & 56,69 & 89,57 \\
\hline N-Gain & 0,3 & $0,8 \%$ \\
\hline Kriteria & Sedang & Tinggi \\
\hline
\end{tabular}

\section{Pembahasan}

Penilaian dari ahli desain media, ahli meteri dan ahli bahasa menunjukkan bahwa media pembelajaran ini sangat layak digunakan dalam pembelajaran (Tabel 4) dengan persentase kelayakan desain media sebesar $91.25 \%$, persentase kelayakan materi sebesar $92 \%$ dan persentase kelayakan bahasa sebesar $100 \%$.

Validator ahli juga memberikan saran perbaikan media. Ahli media memberikan saran agar menyesuaikan tampilan gambar dengan background serta menghilangkan tombol-tombol yang sudah tidak terpakai atau tidak berfungsi lagi. Ahli materi memberikan saran agar lebih menyesuaikan 
beberapa tampilan media antara tulisan dengan backgroud agar terlihat kontras sehingga tulisan dapat terlihat jelas serta perbaikan pada beberapa kesalahan penulisan dan pejelasan gambar.

Hasil akhir penilaian validator ahli mengenai pengembangan media berupa animasi pembelajaran berbasis aplikasi Adobe Flash Professional Cs6 sudah dinyatakan memenuhi kriteri layak sebagai media pembelajaran, sehingga selanjutnya dapat dilakukan uji coba pada responden

Uji coba produk dilakukan dengan uji

Praktikalitas dan Efektivitas media pembelajaran. Uji kepraktisan media pembelajaran dilakukan dengan menyebarkan angket tanggapan kepada Mahasiswa dan Dosen mata kuliah. Berdasarkan tanggapan dari dosen mata kuliah Fisika Dasar I pada (tabel 5) diperoleh persentase kepraktisan sebesar $91 \%$ dengan kriteria sangat praktis. Menurut tanggapan Dosen mata kuliah media yang dikembangkan sudah cukup baik untuk diterapkan pada mata kuliah Fisika Dasar I. Cakupan isi materi nya sudah sesuai dengan tujuan dan capaian pembelajaran, mudah dimengerti, serta tampilan dan bahasa sudah sesuai dengan kaedah yang berlaku. Namun terdapat sedikit perbaikan yaitu agar lebih memperjelas tulisan pada persamaan atau rumus-rumus yang terdapat dalam media. Untuk praktikalitas media berdasarkan tanggapan Mahasiswa kelompok kecil dapat dilihat pada tabel 5 diperoleh persentase kepraktisan sebesar 84\% dengan kriteria sangat praktis. Uji coba praktikalitas kelompok kecil juga mendapatkan beberapa komentar dan saran dari Mahasiswa yaitu terdapat beberapa frame yang tidak cocok antara warna tulisan dengan background, akan tetapi secara keseluruhan media sudah bagus dan menarik. Untuk praktikalitas media berdasarkan tanggapan Mahasiswa kelompok besar dapat dilihat pada tabel 5 diperoleh persentase kepraktisan sebesar $87 \%$ dengan kriteria sangat praktis. Uji coba praktikalitas kelompok besar juga mendapatkan beberapa komentar dan saran dari Mahasiswa yaitu musik (Sound) yang digunakan sebaiknya dihilangkan atau diganti karena membuat konsentrasi belajar terganggu dan membuat mengantuk. Akan tetapi secara umum media pembelajaran dengan aplikasi Adobe Flash Professional Cs6 ini sudah sangat menarik, interaktif dan kreatif baik dalam animasi, tampilan maupun isi materi didalamnya sehingga sangat cocok untuk diaplikasikan pada mata kuliah Fisika Dasar I.

Kemudian untuk uji Efektivitas media pembelajaran dilakukan dengan memberikan sejumlah pertanyaan berbentuk esay untuk melihat hasil tes awal dan tes akhir yang diikuti oleh 35 (tiga puluh lima) orang Mahasiswa semester I Program Studi Tadris Fisika Fakultas Tarbiyah dan Keguruan UIN Sulthan Thaha Saifuddin Jambi. Berdasarkan hasil tes yang dilakukan menunjukkan adanya peningkatan hasil tes. Pada sesi tes pertama sub pokok bahasan kinematika dengan nilai rata-rata pretest (tes awal) sebesar 33,43 dan nilai rata-rata posttest (tes akhir) sebesar 56,69. Setelah dianalisis dengan menggunakan persamaan efektivitas diperoleh tingkat keefektifan sebesar $0.3 \%$ dengan kriteria sedang (tabel 6). Pada sesi test kedua sub pokok bahasan Dinamika nilai rata-rata pretest (tes awal) sebesar 50,29 dan nilai rata-rata posttest (tes akhir) sebesar 89,57. Setelah dianalisis dengan menggunakan rumus efektivitas diperoleh tingkat keefektivan sebesar $0.8 \%$ dengan kriteria Tinggi (tabel 6). Hasil ini sesuai dengan penelitian (Riyadi et al. 2017) yang menggunakan media yang sama pada pokok bahasan yang berbeda yaitu cahaya memperoleh tingkat efektivitas pada kriteria yang baik. (Syefrinando, 2016) juga telah melakukan penelitian yang sama dengan 
kesimpulan media pembelajaran fisika yang sudah didesain dan dikembangkan ini menggunakan aplikasi macromedia flash professional 8 dikatakan baik dan dapat digunakan oleh guru dan siswa sebagai media dalam proses pembelajaran untuk materi Hukum Newton karena sudah ditanggapi oleh siswa dan divalidasi oleh ahli materi dan media.

\section{PENUTUP}

Berdasarkan hasil penelitian dan analisis data yang sudah dilakukan maka disimpulkan bahwa dalam mendesain dan mengembangkan media pembelajaran fisika berbasis Adobe Flash Professional CS6 pada mata kuliah Fisika Dasar I untuk mahasiswa Program Studi Tadris Fisika Fakultas Tarbiyah dan Keguruan UIN Sulthan Thaha Saifuddin Jambi sudah dapat dinyatakan valid, praktis dan efektif dan dapat digunakan sebagai penunjang dalam proses pembelajaran mata kuliah Fisika Dasar I pada pokok bahasan Mekanika (kinematika dan dinamika)

\section{UCAPAN TERIMAKASIH}

Penulis mengucapkan terima kasih kepada semua pihak atas bantuan dan dukungannya sehingga penelitian ini bisa berjalan dan memperoleh hasil yang baik dan juga kepada LP2M. Artikel ini ditulis berdasarkan penelitian yang didanai oleh UIN Sulthan Thaha Saifuddin Jambi dengan Surat Kontrak Kerja Penelitian Dasar Pengembangan Prodi dengan nomor SK: B99/Un.15.LPPM/L.II.2/05/2019

\section{REFERENSI}

Arikunto, S. (2012). Prosedur Penelitian Suatu Pendekatan Praktek. Rineka Cipta.

Gunawan, G., Harjono, A., \& Sutrio, S. (2017). Multimedia Interaktif dalam Pembelajaran Konsep Listrik bagi
Calon Guru. Jurnal Pendidikan Fisika dan Teknologi, 1(1), 9. https://doi.org/10.29303/jpft.v1i1.23 0

Hamalik, O, O. (1980). Media Pendidikan. Alumni. https://books.google.co.id/books?id =Y5_ONwAACAAJ

Jalaluddin, J., \& Abdullah Idi. (2013). Filsafat Pendidikan. Jakarta: Raja Grafindo Persada.

Riduwan. (2012). Dasar dasar Statistik. Alfabeta.

Riyadi, A., Gunawan, G., \& Ardhuha, J. (2017). Pengaruh Penerapan Model Pembelajaran Kontekstual Berbantuan Media Flash Terhadap Pemahaman Konsep Fisika Siswa. Jurnal Pendidikan Fisika dan Teknologi, 1(2), 87-91. http://dx.doi.org/10.29303/jpft.v1i2.2 40

Sahidu, H., Gunawan, G., Rokhmat, J., \& Rahayu, S. (2018). Pengembangan Perangkat Pembelajaran Fisika Berorientasi Pada Kreativitas Calon Guru. Jurnal Pendidikan Fisika dan Teknologi, $\quad 4(1), \quad 1$. https://doi.org/10.29303/jpft.v4i1.44 2

Sugiyono. (2015). Metode Penelitian Kuantitatif Kualitatif dan $R \& D$. Afabeta.

Syefrinando, B. (2016). Pengembangan media pembelajaran berbasis macromedia flash professional 8 . IJER (Indonesian Journal of Educational Research), 1(2), 102. https://doi.org/10.30631/ijer.v1i2.21

Votecamejo. (2018). Adobe Flash, Pengertian dan Perkembangannya. Blog votecamejo. https://www.votecamejo.com/techno logy/adobe-flash-pengertian-danperkembangannya/ 